\title{
Persistent Firing Supported by an Intrinsic Cellular Mechanism in a Component of the Head Direction System
}

\author{
Motoharu Yoshida and Michael E. Hasselmo \\ Center for Memory and Brain, Boston University, Boston, Massachusetts 02215
}

The rat postsubiculum has head direction cells that fire persistently when the rat's head is oriented in particular directions. This persistent firing is maintained even if the rat is motionless, when spatial cues are removed from the environment and in the dark, but the mechanism that supports persistent firing of the head direction cells is still unclear. Here, using in vitro whole-cell patch recording, we found that a short-triggering stimulus (as few as five induced spikes) can initiate persistent firing in cells of the postsubiculum. Pharmacological results indicated that this persistent firing is driven by a calcium-sensitive nonselective cation current. The distribution of cells with persistent firing in superficial and deep layers in the postsubiculum was similar to that of head direction cells. These results suggest that persistent firing of head direction cells in the postsubiculum could be supported by an intrinsic mechanism.

\section{Introduction}

The rat postsubiculum (dorsal presubiculum) (van Groen and Wyss, 1990) has head direction cells that fire when the animal's head is oriented in particular directions (Ranck, 1984; Taube et al., 1990a,b; Sharp, 1996). Firing of head direction cells persists if the animal's head remains in the preferred direction of the cell (Taube and Muller, 1998) and is maintained even when visual cues are removed or in darkness (Taube et al., 1990b; Goodridge et al., 1998). These results suggest that there is an internal mechanism that supports persistent firing of the head direction cells. However, the mechanism for the persistent firing is not known [for review, see Taube and Bassett (2003); Taube (2007)].

Numerous models of head direction system have been proposed to understand the mechanism of the generation of head direction cells (McNaughton et al., 1991; Skaggs et al., 1995; Redish et al., 1996; Zhang, 1996; Goodridge and Touretzky, 2000; Rubin et al., 2001; Boucheny et al., 2005; Song and Wang, 2005). Most of the models used attractor network dynamics to maintain a subset of head direction cells active while keeping the rest quiet, resulting in a subset of cells showing a "hill of activity." In the earlier models, excitatory synaptic connections among nearby head direction cells maintained the hill of activity (Skaggs et al., 1995; Redish et al., 1996; Zhang, 1996; Goodridge and Touretzky, 2000). However, in many of the models, parameters were set for the modeled cells to spontaneously fire, to ensure that the condition where all cells were silent was unstable. Because of the lack of strong anatomical support for excitatory connections, recent models focused on producing a hill of activity only with inhibitory input to the head direction cells (Rubin et al., 2001;

Received Oct. 24, 2008; revised March 19, 2009; accepted March 20, 2009.

This work was supported by National Institute of Mental Health (NIMH) Grants MH61492 and MH60013; Silvio 0. Conte Center NIMH Grants MH71702 and MH60450; and Japan Society for the Promotion of Science, Postdoctoral Fellowship for Research Abroad. We appreciate useful discussions with Charlotte Boccara and Mark Brandon.

Correspondence should be addressed to Motoharu Yoshida, Center for Memory and Brain, 2 Cummington Street, Boston University, Boston, MA 02215. E-mail: motoharu@bu.edu.

DOI:10.1523/JNEUROSCI.5154-08.2009

Copyright $\odot 2009$ Society for Neuroscience $\quad 0270-6474 / 09 / 294945-08 \$ 15.00 / 0$
Boucheny et al., 2005; Song and Wang, 2005). These recent models assumed external excitatory input to ensure the persistent firing of head direction cells. However, the origins of the spontaneous firing or external input used to ensure persistent firing in these models are unclear.

Recent in vitro studies have unveiled persistent firing that solely depends on an intracellular mechanism. In the entorhinal cortex, during activation of $\mathrm{M}_{1}$ muscarinic receptors (Klink and Alonso, 1997; Egorov et al., 2002; Tahvildari et al., 2007) or the metabotropic glutamate receptors (Al-Yahya et al., 2003; Yoshida et al., 2008), a short-triggering stimulus activates a calciumactivated nonselective cationic current $\left(I_{\mathrm{CAN}}\right)$ which then leads to persistent firing. Intrinsic persistent firing would be an ideal mechanism for ensuring persistent firing of the head direction cells. However, electrophysiological properties of neurons in the head direction system are poorly understood. In particular, it has not been shown if intrinsic persistent firing exists in the head direction system. In this study, using whole-cell patch recording techniques in in vitro slice preparations, we investigated the presence of intrinsic persistent firing in the rat postsubiculum, which is estimated to have the largest number of head direction cells in the head direction system (Taube and Bassett, 2003).

\section{Materials and Methods}

Slice preparation. All experimental protocols were approved by the Institutional Animal Care and Use Committee at Boston University. LongEvans rats (postnatal days 21-27; Charles River) were deeply anesthetized with ketamine/xylazine $(95 \mathrm{mg} / \mathrm{Kg}$ ketamine and $2.8 \mathrm{mg} / \mathrm{Kg}$ xylazine) through intraperitoneal injection. After the absence of both pedal and tail pinch reflex was confirmed, ice-cold modified artificial CSF (ACSF) containing (in mM) 110 choline chloride, $2.5 \mathrm{KCl}, 1.25$ $\mathrm{NaH}_{2} \mathrm{PO}_{4}, 26 \mathrm{NaHCO}_{3}, 0.5 \mathrm{CaCl}_{2}, 7 \mathrm{MgCl}_{2}, 7$ glucose, 3 pyruvic acid, and 1 ascorbic acid (pH adjusted to 7.4 by saturation with $95 \% \mathrm{O}_{2}-5 \%$ $\mathrm{CO}_{2}$ ) was intracardially perfused. The brain was then removed from the cranium and placed in ice-cold modified ACSF. Slices (350 $\mu \mathrm{m}$ thick) were cut sagittally or horizontally using a Vibroslicer (World Precision Instruments). Slices were transferred to a holding chamber, where they were kept submerged at $30^{\circ}$ for $30 \mathrm{~min}$ and then at room temperature at 
least 30 more minutes before recording. The holding chamber was filled with ACSF containing (in mM) $124 \mathrm{NaCl}, 3 \mathrm{KCl}, 1.25 \mathrm{NaH}_{2} \mathrm{PO}_{4}, 26$ $\mathrm{NaHCO}_{3}, 1.6 \mathrm{CaCl}_{2}, 1.8 \mathrm{MgSO}_{4}, 10$ glucose (pH adjusted to 7.4 by saturation with $95 \% \mathrm{O}_{2}-5 \% \mathrm{CO}_{2}$ ).

Electrophysiological recording. Slices were transferred to a submerged recording chamber and superfused with ACSF, maintaining the temperature in between 34 and $36^{\circ} \mathrm{C}$ for recordings. Patch pipettes were fabricated from borosilicate glass capillaries by means of a P-87 horizontal puller (Sutter Instrument). Patch pipettes were filled with intracellular solution containing (in mM) $120 \mathrm{~K}$-gluconate, 10 HEPES, 0.2 EGTA, 20 $\mathrm{KCl}, 2 \mathrm{MgCl}, 7$ phosphocreatine-diTris, $4 \mathrm{Na}_{2} \mathrm{ATP}$, and 0.3 Tris $\mathrm{GTP}$ ( $\mathrm{pH}$ adjusted to 7.3 with $\mathrm{KOH}$ ). The intracellular solution also contained $0.1 \%$ biocytin for the purpose of labeling. When filled with this solution, the patch pipettes had a resistance of 3-5 M $\Omega$. Slices were visualized with an upright microscope (Zeiss Axioskop 2), equipped with a $\times 40$ waterimmersion objective lens, and a near-infrared charge-coupled device camera (JAI CV-M50IR). Locations of the cells in the slice were confirmed by biocytin staining after recording in $70 \%$ of the cells. Tight seals $(>1 \mathrm{G} \Omega)$ were formed on cell bodies, and the membrane was ruptured with negative pressure. Current-clamp recordings were made with a MultiClamp 700B amplifier (Axon Instruments) using a built-in bridge balance and capacitance compensation circuits. Signals were low-pass filtered at 5 or $10 \mathrm{kHz}$ and sampled at 10 or $20 \mathrm{kHz}$, respectively, using Clampex 9.0 software (Axon Instruments). A liquid junction potential of $10 \mathrm{mV}$ was not corrected.

The calcium-free ACSF was prepared by replacing $\mathrm{CaCl}_{2}$ in the ACSF with $3.2 \mathrm{~mm} \mathrm{MgCl}_{2}$. Stock solutions of charbachol (10 mM, in water) and flufenamic acid (100 mM, in dimethyl sulfoxide) were prepared and diluted $1000 \times$ or more in the ACSF. Kynurenic acid and picrotoxin were directly dissolved in the ACSF. Chemicals were purchased from SigmaAldrich and Tocris Bioscience.

To determine the baseline membrane potential before induction of persistent firing, we slowly depolarized the membrane potential using increments of $0.3 \mathrm{pA}$ until the cell started firing. The amplitude of the current just before the cell started firing was used as the amplitude of the baseline current. Induction of persistent firing was tested after confirming that the baseline potential was not drifting more than $\sim 2 \mathrm{mV}$ for at least $5 \mathrm{~s}$.

Data analysis. Clampfit 9.0 (Axon Instruments) and Matlab (MathWorks) were used for data analysis. Frequency of persistent firing was measured as an average firing frequency of the neuron during the period between 10 and $30 \mathrm{~s}$ after the termination of the current injection. The poststimulus potential was measured as the difference between an average membrane potential during the same period $(10-30 \mathrm{~s})$ and the baseline membrane potential which was measured as an average of the membrane potential for a period of at least $3 \mathrm{~s}$ just before current injection. Number of spikes during stimulation was measured as the number of spikes elicited during stimulation period.

Sag potential was analyzed using the voltage deflection of membrane potential by a $1 \mathrm{~s}$ hyperpolarization current $(-60$ to $-150 \mathrm{pA})$ which produced a negative peak potential (see Fig. $5 b$, arrow) between -76 to $-91 \mathrm{mV}$. The steady state potential for sag was measured as an average membrane potential during the last $200 \mathrm{~ms}$ period of current injection (see Fig. $5 b$, line and filled circle). Sag ratio was calculated by dividing the difference between the peak and the steady state potential by the difference between the peak and the baseline potential.

Distances of recorded neurons from forceps major corpus callosum (fmj) (Fig. 5c) was measured as the distance from the border between the fmj and the postsubiculum deep layer (see Fig. $4 a$, dotted lines) to a stained cell body.

Spike frequency adaptation ratio was calculated by dividing the last interspike interval by the first interspike interval. Input resistance was measured from a voltage deflection by a $5 \mathrm{pA}$ hyperpolarizing current injection for $500 \mathrm{~ms}$ at a starting membrane potential of $-65 \mathrm{mV}$. Spike threshold and spike half-width were measured from a trace during a $1 \mathrm{~s}$ depolarizing current. Traces with at least three spikes were used. Measurements from three spikes were averaged.

Significance levels were evaluated using paired and unpaired $t$ tests.
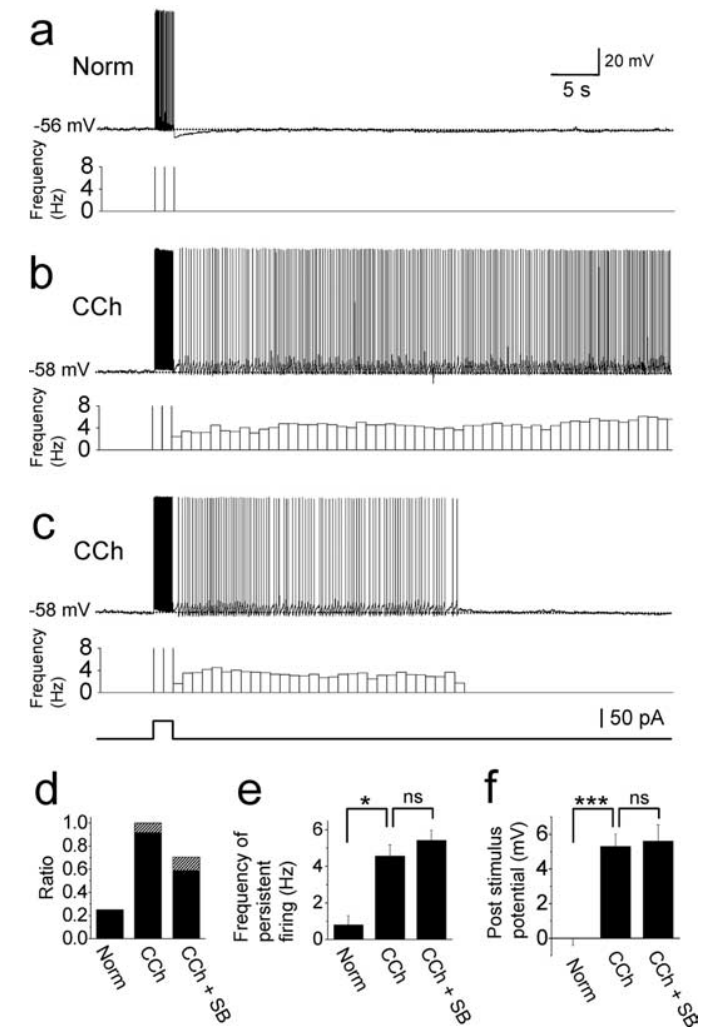

Figure 1. Persistent firing of postsubicular neurons. $\boldsymbol{a}$, Current injection $(2 \mathrm{~s}, 50 \mathrm{pA})$ drove firings but did not induce persistent firing in the control ACSF. $\boldsymbol{b}$, Persistent firing was induced by the same current injection in the presence of carbachol $(10 \mu \mathrm{m})$ in the same cell as in $\boldsymbol{a}$. Bottom trace shows frequency of persistent firing. $c$, Example of self-terminating persistent firing in carbachol in a different cell from above. Bottom trace shows timing of $2 \mathrm{~s}$ current injection for $\boldsymbol{a}-\boldsymbol{c}$. $\boldsymbol{d}$, Ratios of cells with persistent firing (filled) and self-terminating persistent firing (hatched) in normal ACSF (Norm), carbachol (CCh), and carbachol plus synaptic blockers (CCh + SB). $\boldsymbol{e}$, Frequency of persistent firing. $\boldsymbol{f}$, Poststimulus potential.

Significance level $<0.05$ (ns, not significant; ${ }^{\star} p<0.05,{ }^{\star *} p<0.01$, $\left.{ }^{* * *} p<0.001\right)$ was used. Data are expressed as means \pm SEM.

\section{Results}

\section{Persistent firing of postsubicular neurons}

We first investigated if postsubiculum neurons demonstrate persistent firing in normal ACSF. Recordings were made in neurons from both superficial and deep layers, regardless of their cell type (pyramidal or stellate cells). The membrane potential was adjusted to just below firing threshold by applying constant current injection. In the following, we denote this potential the "baseline" membrane potential (see Materials and Methods). By setting the baseline membrane potential just below the firing threshold, persistent firing could be studied and compared among different neurons and pharmacological conditions. After confirming that the baseline potential was not drifting $>2 \mathrm{mV}$ for $5 \mathrm{~s}$, we injected a 2 s suprathreshold current pulse with an amplitude of 50-150 pA. In normal ACSF, membrane potential simply went back to the baseline potential after the stimulation in $75 \%$ (9 of 12) of the cells (Fig. 1a,d). However, in the rest of the cells (25\%), membrane potential was depolarized after termination of the stimulation and drove persistent firing with a very low frequency $(0.8 \pm$ $0.5 \mathrm{~Hz}, n=3$, trace not shown) (Fig. $1 d, e$ ).

Acetylcholine levels rise during waking behavior (Marrosu et al., 1995) because of cholinergic innervation arising from subcortical structures (Mesulam et al., 1983). Thus, waking behavior is associated with greater cholinergic modulation than present in 
our control ACSF. During perfusion of the cholinergic receptor agonist carbachol (CCh; $10 \mu \mathrm{M})$, the same current injection was followed by persistent firing in $92 \%$ ( 11 of 12 ) of the same postsubicular cells (Fig. $1 d, \mathrm{CCh}$ ). Figure $1 b$ shows an example of the persistent firing in carbachol in the same cell as in Figure $1 a$. Firing could persist for up to $2.5 \mathrm{~min}$, after which it was terminated by hyperpolarizing current injection. The frequency of persistent firing with carbachol was significantly higher than that in normal ACSF $\left(4.6 \pm 0.6 \mathrm{~Hz}, n=11\right.$, unpaired $t$ test, $t_{13}=3.0, p<$ $0.05)$ (Fig. 1e, CCh). The remaining one cell showed selfterminating persistent firing which stopped firing within $30 \mathrm{~s}$ (Fig. 1c,d).

To examine the contribution of fast ionotropic synaptic transmission to the persistent firing, we tested the effect of synaptic blockers in a different set of cells. In these experiments, the cholinergic agonist carbachol and synaptic blockers were added to the ACSF perfusing the slice preparation before the start of the recording. Synaptic blockers included kynurenic acid ( $2 \mathrm{mM})$ and picrotoxin $(100 \mu \mathrm{M})$ to suppress ionotropic glutamate receptors and $\mathrm{GABA}_{\mathrm{A}}$ receptors, respectively. In this condition, the same current injection induced persistent firing in 59\% (20 of 34) of the cells and self-terminating persistent firing in 12\% (4 of 34) of the cells (Fig. $1 d$, CCh $+\mathrm{SB}$ ). The frequency of persistent firing was similar to that without synaptic blockers $(5.4 \pm 0.6 \mathrm{~Hz}, n=$ 20 , unpaired $t$ test, $\left.t_{28}=0.97, p=0.34\right)$ (Fig. 1e, CCh $+\mathrm{SB}$ ).

Figure 1e compares the frequency of persistent firing only in cells that showed persistent firing. In addition, to compare the effect of the three different conditions above including cells without persistent firing, we measured the membrane potential difference after stimulation (poststimulus potential, measured as the difference between membrane potential 10-30 s after termination of stimulation and the baseline membrane potential; see Materials and Methods) (Fig. 1f). The poststimulus potential significantly increased with the application of carbachol $(n=12$, paired $t$ test, $t_{11}=-8.5, p<0.001$ ), but it did not change significantly with the additional presence of synaptic blockers (unpaired $t$ test, $t_{45}=0.19, p=0.85$ ). The poststimulus potential was measured using membrane potential traces including spikes. When spikes were removed by excluding segments from $1 \mathrm{~ms}$ before to $2 \mathrm{~ms}$ after each spike, poststimulus potential was only $0.40 \pm 0.07 \mathrm{mV}(n=34)$ lower in the presence of carbachol and synaptic blockers compared with the measurement which included spikes $(5.61 \pm 0.94 \mathrm{mV}$ with spikes and $5.21 \pm 0.88 \mathrm{mV}$ without spikes, $n=34)$. Thus, the difference was less than half of the SE, and therefore, inclusion of spikes in the measurement does not affect the significance of results. These results suggest that postsubicular cells can support persistent firing and that persistent firing can be induced intrinsically independent of synaptic transmission.

\section{Effects of extracellular calcium and flufenamic acid}

To give more insight into the mechanism of persistent firing, we next tested the effect of extracellular calcium. In control conditions, persistent firing was induced in the presence of carbachol $(10 \mu \mathrm{M})$ and synaptic blockers ( $2 \mathrm{~mm}$ kynurenic acid and $100 \mu \mathrm{M}$ picrotoxin) (Fig. 2a). The extracellular solution was then switched to a calcium-free ACSF (see Materials and Methods). Persistent firing was completely blocked in all eight cells tested in calcium-free ACSF (Fig. 2b). Both the frequency of persistent firing (measured in all cells, $n=8$ ) (Fig. 2e, left) (paired $t$ test, $t_{7}$ $=6.9, p<0.001)$ and the membrane potential difference after stimulation $(n=8)$ (Fig. $2 f$, left) (paired $t$ test, $t_{8}=5.8, p<0.001$ ) were significantly reduced in the absence of calcium.
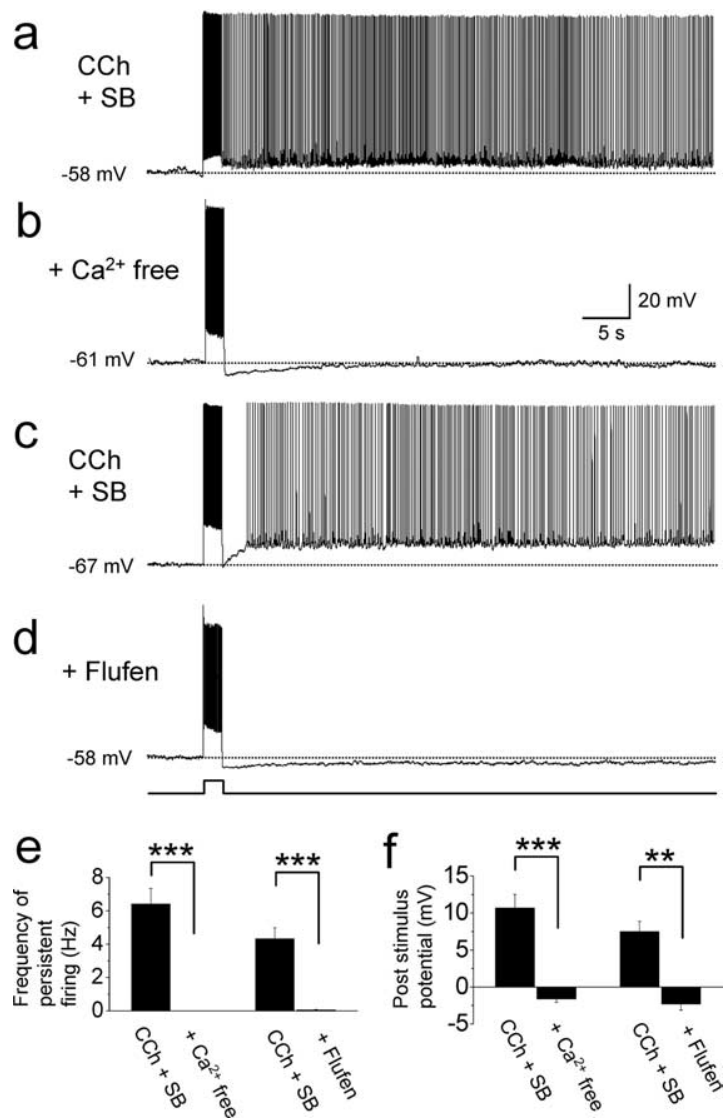

Figure 2. Effects of extracellular calcium and flufenamic acid. $\boldsymbol{a}$, Induction of persistent firing in carbachol plus synaptic blockers (CCh + SB; $10 \mu \mathrm{m}$ carbachol, 2 mm kynurenic acid, and 100 $\mu \mathrm{m}$ picrotoxin). $\boldsymbol{b}$, Persistent firing was not induced when a calcium-free version of the same solution was used in the same cell as in $\boldsymbol{a}$. $\boldsymbol{c}$, Induction of persistent firing in carbachol plus synaptic blockers (CCh + SB; $10 \mu \mathrm{m}$ carbachol, 2 mm kynurenic acid, and $100 \mu \mathrm{m}$ picrotoxin). d, Persistent firing was blocked when the same solution was used with addition of flufenamic acid ( $100 \mu \mathrm{m})$ in the same cell as in c. Amplitudes of current injections were $50 \mathrm{pA}$ for $\boldsymbol{a}$ and $\boldsymbol{b}$, and $150 \mathrm{pA}$ for $\boldsymbol{c}$ and $\boldsymbol{d}$. $\boldsymbol{e}$, Frequency of persistent firing. $\boldsymbol{f}$, Poststimulus potential. Flufen, Flufenamic acid.

We tested the effect of flufenamic acid, a blocker of the calcium-sensitive nonselective cationic current $\left(I_{\mathrm{CAN}}\right)$, on persistent firing. In seven cells which showed persistent firing in the presence of carbachol and synaptic blockers (Fig. 2c), we applied flufenamic acid (100 $\mu \mathrm{M})$ (Fig. $2 d)$. Both the frequency of persistent firing (measured in all cells, $n=7$ ) (Fig. 2e, right) (paired $t$ test, $\left.t_{5}=6.3, p<0.001\right)$ and the membrane potential difference after stimulation $(n=7)$ (Fig. $2 f$, right) (paired $t$ test, $t_{5}=5.0, p<$ 0.01 ) were significantly reduced in the presence of flufenamic acid.

The baseline potential was more depolarized in the presence of flufenamic acid with carbachol than in the condition with carbachol alone $(-59.9 \pm 2.1 \mathrm{mV}$ in carbachol and $-55.3 \pm 1.7$ $\mathrm{mV}$ in flufenamic acid plus carbachol). In carbachol alone, cells had a tendency to depolarize easily to cause spikes even from relatively hyperpolarized potential, presumably attributable to the activation of $I_{\mathrm{CAN}}$. In the presence of flufenamic acid plus carbachol, the baseline potential was able to be set to a more depolarized level since cells did not have this tendency, presumably because of the blockade of $I_{\mathrm{CAN}}$. One could argue that persistent firing should be induced from the same baseline potential in these two conditions. Judging from previous studies (Egorov et al., 2002; Yoshida et al., 2008), it is easier to induce persistent firing from a more depolarized level than from a more hyperpo- 
larized level. The goal of this section was to show blockade of persistent firing by flufenamic acid. Using the same baseline potential would leave it unclear if persistent firing can still be induced when the membrane potential is set to a more depolarized level. To avoid this uncertainty, we showed the lack of persistent firing at the most depolarized baseline in flufenamic acid plus carbachol where it should be the easiest to induce persistent firing. These results suggest that persistent firing in these postsubicular cells was induced by $I_{\mathrm{CAN}}$, similar to the cells from entorhinal cortex (Egorov et al., 2002; Tahvildari et al., 2008).

\section{Induction of persistent firing with short current injection}

Most of the head direction cell models use input from angular velocity-sensitive cells to the head direction cells to achieve direction-selective firing (McNaughton et al., 1991; Skaggs et al., 1995; Redish et al., 1996; Goodridge and Touretzky, 2000; Boucheny et al., 2005; Song and Wang, 2005). The postsubiculum also has angular velocity-sensitive cells (Sharp, 1996) which could give input to head direction cells. However, angular velocity-sensitive cells may not fire for durations as long as $2 \mathrm{~s}$ depending on how slowly the animal turns its head. Therefore, we next examined the effect of short current injection on the induction of persistent firing. In 13 neurons (seven with and six without synaptic blockers) that showed persistent firing with the $2 \mathrm{~s}$ current injection in carbachol, we further tested $200 \mathrm{~ms}$ current injection. Persistent firing was observed in 8 of the 13 cells $(62 \%$, three with and five without synaptic blockers) with $200 \mathrm{~ms}$ stimulation.

We compared persistent firing induced by $2 \mathrm{~s}$ and $200 \mathrm{~ms}$ injections in these eight cells (Fig. 3). Figure 3, $a$ and $b$, shows persistent firing induced in the same cell with $2 \mathrm{~s}$ and $200 \mathrm{~ms}$ current injection protocols, respectively. Although $200 \mathrm{~ms}$ stimulation induced a dramatically smaller number of spikes during stimulation (six spikes) than did $2 \mathrm{~s}$ stimulation (77 spikes), the resulting frequency of persistent firing was not significantly different between the two different stimulation protocols $(5.2 \mathrm{~Hz}$ with $2 \mathrm{~s}$ and $4.6 \mathrm{~Hz}$ with $200 \mathrm{~ms}$ stimulation). Figure 3, $c$ and $d$, shows another example. This cell showed relatively lowfrequency persistent firing both after $2 \mathrm{~s}$ stimulation and after 200 ms stimulation (2.2 and $2.6 \mathrm{~Hz}$, respectively). In a similar manner, the frequency of persistent firing of other cells was different among cells but did not dramatically differ between $2 \mathrm{~s}$ and 200 ms stimulation protocols (Fig. 3e). In summary, the frequency of persistent firing induced by $2 \mathrm{~s}$ and $200 \mathrm{~ms}$ stimulation protocols were not significantly different $(5.6 \pm 0.8$ and $5.1 \pm 0.5 \mathrm{~Hz}$, respectively; $n=8$, paired $t$ test, $t_{7}=1.5, p=0.17$ ). The membrane potential difference after stimulation did not differ significantly between the two stimulation protocols as well $(9.8 \pm 1.8$ and $8.3 \pm 1.8 \mathrm{mV}$, respectively; $n=8$, paired $t$ test, $t_{7}=1.6, p=$ $0.15)$, whereas the number of spikes during stimulation was significantly different in the two stimulation protocols (51 \pm 5 and $6 \pm 1$, respectively; $n=8$; paired $t$ test, $t_{7}=9.7, p<0.001$ ). These results indicate that stimulation as short as $200 \mathrm{~ms}$ is sufficient for many of neurons in the postsubiculum to initiate persistent firing, and these cells tend to show persistent firing with a frequency unique to the cell and relatively independent from the duration of the stimulation.

\section{Difference between superficial and deep layers}

Taube et al. (1990a) reported that head direction cells were found mainly in deep layers, whereas some head direction cells were found also in superficial layers of the postsubiculum. Recently, Boccara et al. (2008) reported the existence of head direction cells

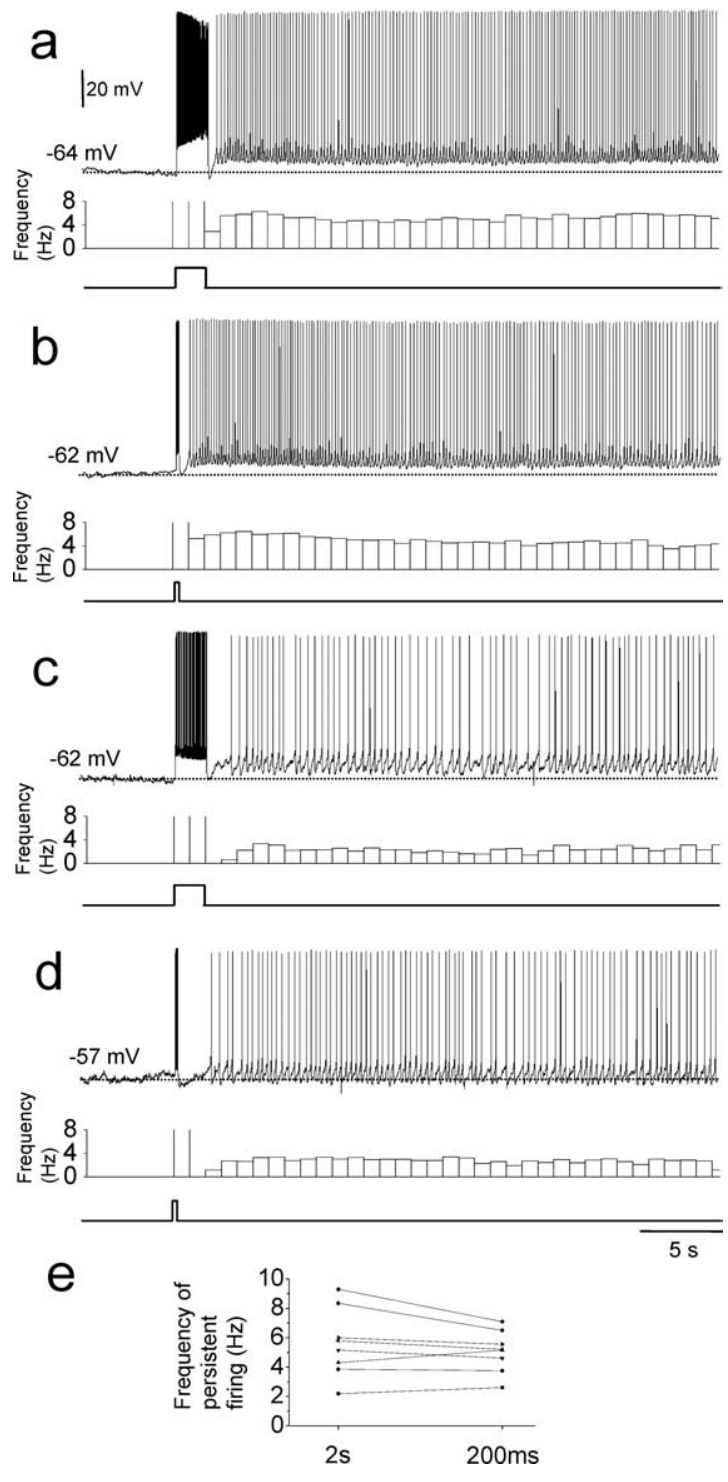

Figure 3. Induction of persistent firing with short current injection. Persistent firing recorded in one cell with $2 \mathrm{~s}(\boldsymbol{a})$ and $200 \mathrm{~ms}(\boldsymbol{b})$ current injection. Persistent firing recorded in another cell with $2 s(\boldsymbol{c})$ and $200 \mathrm{~ms}(\boldsymbol{d})$ current injection. Note that frequency of persistent firing was different between these two cells but was similar in the two stimulation protocols for each cell. $\boldsymbol{e}$, Frequency of persistent firing of individual cells with $2 \mathrm{~s}$ and $200 \mathrm{~ms}$ current injections.

in both deep and superficial layers in the postsubiculum using a different statistical criterion that included a wider range of cells than in the previous studies. We examined the distribution of cells with persistent firing in superficial (layer II and II) and deep layers (layer V and VI) using cells mentioned in the previous sections. The location of the cell was identified using a lowmagnification objective after recording, and it was confirmed by biocytin labeling in $70 \%$ of the cells (Fig. $4 a$ ). In carbachol, $58 \%$ (11 of 19) of the cells from the superficial layers showed persistent firing and $26 \%$ ( 5 of 19) showed self-terminating persisting firing (Fig. $4 b$, left). In the deep layers, 79\% (22 of 28) of the cells showed persistent firing and none showed self-terminating persistent firing (Fig. $4 b$, right). Among the cells with persistent firing, the average frequency of persistent firing was $4.4 \pm 0.7 \mathrm{~Hz}$ $(n=11)$ and $5.5 \pm 0.5 \mathrm{~Hz}(n=20)$ in the superficial and deep layers, respectively (unpaired $t$ test, $t_{29}=1.31, p=0.20$ ). The poststimulus potential was $3.9 \pm 0.7 \mathrm{mV}(n=19)$ and $6.5 \pm 1.0$ $\mathrm{mV}(n=28)$ in the superficial and deep layers, respectively (un- 


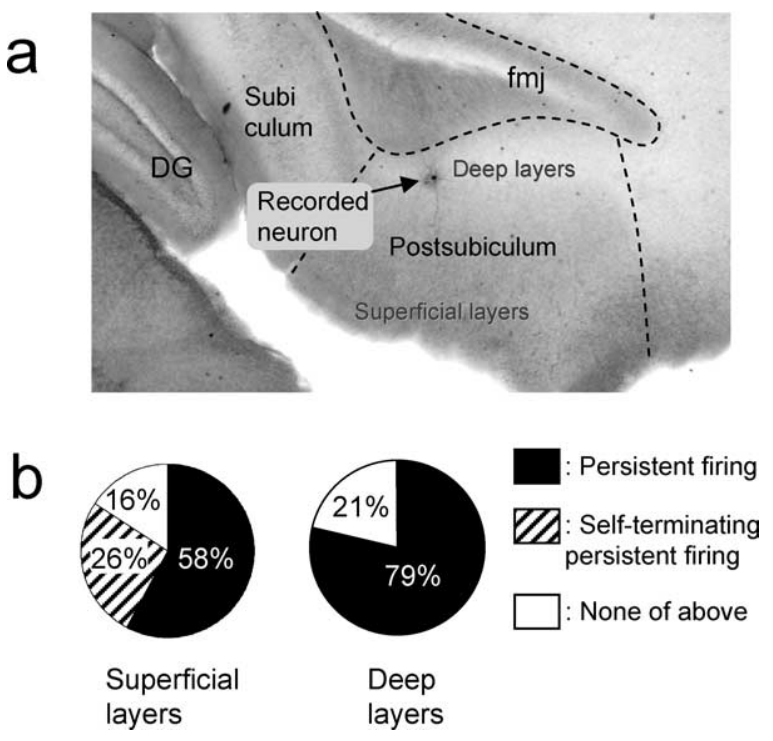

Figure 4. Comparison of superficial and deep layers. $\boldsymbol{a}$, Biocytin-stained postsubicular neuron in a sagittal brain slice. $\boldsymbol{b}$, Ratios of cells with persistent firing (filled) and self-terminating persistent firing (hatched) in superficial (left) and deep layers (right). DG, Dentate gyrus.

paired $t$ test, $\left.t_{45}=1.83, p=0.074\right)$. These results indicate that cells from both superficial and deep layers show persistent firing, whereas self-terminating persistent firing was observed only from superficial cells. If we do not include self-terminating persistent firing cells, however, the deep layer has a slightly larger probability of finding cells with persistent firing (58 and 79\% in superficial and deep layers, respectively), and they tend to show persistent firing with higher frequency $(4.4 \pm 0.7$ and $5.5 \pm 0.5$ $\mathrm{Hz}$ in superficial and deep layers, respectively) and larger depolarization $(3.9 \pm 0.7$ and $6.5 \pm 1.0 \mathrm{mV}$ in superficial and deep layers, respectively).

These analyses were conducted using recordings both with and without synaptic blockers. When only recordings with synaptic blockers were analyzed, 33 and $44 \%$ of cells showed persistent and self-terminating persistent firing, respectively, in the superficial layers $(n=9)$. In the deep layers, $68 \%$ of cells showed persistent firing and none showed self-terminating persistent firing $(n=25)$. Neither frequency of persistent firing nor poststimulus potential significantly differed in superficial and deep layers (data not shown).

In a limited number of cells $(n=16)$, we were able to analyze the relation between persistent firing and anatomical cell types. Out of 16 cells, eight cells were pyramidal, and the other eight cells were stellate cells. In the superficial layers, three of four pyramidal and two of two stellate cells showed persistent firing. In the deep layers, three of four pyramidal and six of six stellate cells showed persistent firing. These data suggest that persistent firing can be found in both pyramidal and stellate cells in both superficial and deep layers. Previous studies have not determined whether head direction cells in the postsubiculum correspond to the morphological categories of pyramidal or stellate cells or to both categories of cells.

\section{Electrophysiological properties}

Electrophysiological properties of postsubiculum cells have not been intensively explored. We tested basic electrophysiological properties of the postsubiculum cells in carbachol and in normal ACSF. One second hyperpolarizing and depolarizing currents (a standard method to study electrophysiological properties) were applied from membrane potential at $-65 \mathrm{mV}$. Hyperpolarizing constant current injections were used to examine the "sag" potential in superficial and deep layer cells in carbachol (Fig. 5a,b). We found that sag ratio (Materials and Methods) is significantly larger in cells from deep layers $(0.14 \pm 0.02, n=23)$ than in superficial layers $\left(0.04 \pm 0.01, n=16\right.$, unpaired $t$ test, $t_{37}=5.2$, $p<0.001)$. As shown in Figure $5 c$, sag ratio monotonically increased as the location of the cell approaches the fmj (Fig. 4a) (linear regression, $r=-0.44 ; p=0.028$ ). The sag ratio tended to be larger in the cells from deep layers than superficial cells in the absence of carbachol as well (data not shown).

We examined if sag ratio is correlated with the persistent firing. We divided the cells into two groups with sag ratio smaller than 0.1 and larger than 0.1 . The ratios of cells with persistent firing were similar in both groups (56 and 61\%, respectively). The frequency of persistent firing (Fig. $5 e$, left) $(n=10$ and 14, respectively; unpaired $t$ test, $\left.t_{22}=1.27, p=0.22\right)$ and depolarization after stimulation (Fig. $5 f$, left) $(n=18$ and 25 , respectively; unpaired $t$ test, $t_{41}=1.18, p=0.24$ ) were not significantly different in groups with sag ratio smaller than 0.1 and larger than 0.1 .

Cellular firing patterns were observed during $1 \mathrm{~s}$ depolarizing current injections (Fig. 5a,b). Some cells (two cells in carbachol, one cell in normal ACSF, and one cell in both conditions) showed single bursts at the onset of current injection, but none of the cells showed repeated burst firing either in carbachol or in normal $\operatorname{ACSF}$ ( $n=43$ and 24, respectively). The spike frequency adaptation rate was measured by comparing the first interspike interval and the last interspike interval (Materials and Methods). Frequency of persistent firing tended to be lower as the adaptation ratio gets higher (Fig. $5 d$ ) (linear regression, $r=-0.38$; $p=$ $0.015)$. When cells were divided into two groups with adaptation ratio smaller than $1.5(n=32)$ and larger than $1.5(n=9)$, the frequency of persistent firing was significantly lower (unpaired $t$ test, $t_{39}=-3.8, p<0.001$ ) (Fig. $5 e$, right), and poststimulus potential was significantly smaller (unpaired $t$ test, $t_{39}=-3.8$, $p<0.001$ ) (Fig. 5f, right) in the group with adaptation ratio larger than 1.5. These results indicate that the amount of afterhyperpolarization (AHP) current influences the frequency of persistent firing.

Resting membrane potential and input resistance were $76.0 \pm$ $1.1 \mathrm{mV}(n=13)$ and $287.5 \pm 30.8 \mathrm{M} \Omega(n=13)$, respectively, in normal ACSF. The frequency of persistent firing measured in carbachol was not correlated with the membrane potential in normal ACSF (linear regression, $r=-0.31 ; p=0.30$ ) or in carbachol (linear regression, $r=-0.31 ; p=0.12$ ). The frequency of persistent firing measured in carbachol was negatively correlated with the input resistance measured in normal ACSF (linear regression, $r=-0.57 ; p=0.011$ ), whereas it was not correlated with the input resistance measured in carbachol (linear regression, $r=-0.02 ; p=0.9)$. Although this correlation between the input resistance in normal ACSF and persistent firing in carbachol is an interesting observation, the lack of correlation between these two measurements in carbachol makes it difficult to interpret this result. The frequency of persistent firing measured in carbachol was not correlated either with the spike threshold (linear regression, $r=-0.15 ; p=0.5$ and $r=-0.18$; $p=0.25$ ) or with the spike half-width (linear regression, $r=-0.33 ; p=0.13$ and $r=0.04 ; p=0.80$ ) measured in normal ACSF and carbachol, respectively.

In this study, we used both positive and negative currents to maintain baseline potentials. Baseline current amplitudes used in different pharmacological conditions were as follows. In control conditions (normal ACSF), the mean baseline current amplitude 
was $88.0 \pm 11.7 \mathrm{pA}$ (ranging from 27.8 to $119.3 \mathrm{pA}, n=12$ ). In carbachol, the mean current was only $9.0 \pm 8.0 \mathrm{pA}$ (ranging from -115.7 to $130.7 \mathrm{pA}, n=51)$. In calcium-free condition (with carbachol) the mean current was $-66.4 \pm 21.1 \mathrm{pA}$ (ranging from -132.2 to $7.1 \mathrm{pA}, n=8$ ). In flufenamic acid (with carbachol), the mean current was $31.5 \pm 16.7 \mathrm{pA}$ (ranging from -16.5 to $116.0 \mathrm{pA}, n=7)$.

\section{Discussion}

In this study, we showed that a majority of cells in the postsubiculum support persistent firing through an intrinsic mechanism. We have indicated that the activation of $I_{\text {CAN }}$ could be the crucial intrinsic mechanism. We also have shown that input to postsubiculum cells as short as 200 ms, which induced only six spikes on average, might be sufficient to initiate this persistent firing. These results suggest that intrinsic persistent firing could be an important mechanism that supports persistent firing of head direction cells in the absence of other sensory input.

The postsubiculum occupies the highest level of the head direction system (Taube and Bassett, 2003). Head direction cells in postsubiculum code the current head direction, whereas head direction cells in the anterodorsal thalamic nucleus $(\mathrm{ADN})$ and lateral mammillary nucleus anticipate head direction (Blair and Sharp, 1995; Blair et al., 1998; Stackman and Taube, 1998; Taube and Muller, 1998). This head direction signal spreads to the entorhinal cortex where it can be integrated with place and grid cell information (Taube, 2007). This head direction input could be important for path integration during navigation, and generation of grid cell firing properties in medial entorhinal cortex (McNaughton et al., 2006; Burgess et al., 2007; Hasselmo et al., 2007; Hasselmo and Brandon, 2008). In a model of the encoding and replay of trajectories, intrinsic persistent firing in head direction cells allows continuous updating of entorhinal grid cell representations for replay (Hasselmo, 2008; Hasselmo and Brandon, 2008) and could contribute to replay of head direction activity during REM sleep (Brandon et al., 2008).

Taube et al. (1990b) reported that most postsubicular head direction cells were recorded in the deep layers, whereas some were found also in superficial layers, and the percentage of head direction cells was $25 \%$. Sharp (1996) reported that $37 \%$ of cells were head direction cells in the postsubiculum. A recent study used a different statistical criterion that included a wider range of cells than in the previous studies (Boccara et al., 2008) and showed that the percentage of head direction cells in deep layers is $\sim 60 \%$ and in superficial layers is $\sim 55 \%$. We found in our study that persistent firing can be found in the deeper layer with higher (nearly $80 \%$ ) (Fig. $4 b$ ) probability than in the superficial layer (nearly 60\%) (Fig. 4b). In vivo electrophysiological data will be necessary to conclude that head direction cells are among the cells that show persistent firing. However, our data suggest that head direction cells could be a subpopulation of cells that show persis- tent firing, and the higher percentage of head direction cells found in deeper layers could be related to the higher percentage of cells with intrinsic persistent firing in these layers.

Head direction cells in the postsubiculum and ADN lose their firing after peripheral vestibular inhibition or lesion (Stackman and Taube, 1997; Stackman et al., 2002). However, head direction cell models which use a hill of activity supported by attractor dynamics will not stop firing when external input is removed. This is one way that models using a hill of activity do not fit experimental observation (Taube and Bassett, 2003). In contrast, if intrinsic persistent firing is used, the need for brief external input to trigger persistent firing can resolve this inconsistency between model and experimental data.

Firing frequency of some head direction cells observed in in vivo studies are in the range of the frequency of persistent firing we observed in this study $(<10 \mathrm{~Hz})$ (Taube et al., 1990a; Boccara et al., 2008; Brandon et al., 2008). However, firing frequency of head direction cells is often $>20 \mathrm{~Hz}$ (Taube et al., 1990a). This higher frequency could result from synaptic effects. When multiple neurons that are connected by excitatory synapses undergo persistent firing simultaneously, positive feed back through synaptic network could speed up firing.

We observed persistent firing with very low frequency even in the absence of carbachol in $25 \%$ of cells (Fig. 1d,e). It is reported that a smaller amount of $I_{\text {CAN }}$ can be activated solely by the in- 
crease in the intracellular calcium level (Gee et al., 2003). Therefore, an increase in the calcium level attributable to depolarization during stimulation may have activated a small amount of $I_{\mathrm{CAN}}$ and induced persistent firing in the absence of carbachol. However, for this small persistent firing to contribute to the head direction system, some other mechanism has to depolarize the neurons similar to the $88.0 \mathrm{pA}$ of direct current (DC) we injected. Moreover, the frequency of persistent firing observed in the absence of carbachol was very low. However, the fact that we used only $9.0 \mathrm{pA}$ of DC current injection in carbachol to set the baseline potential suggests that the physiological resting membrane potential during cholinergic activation could be suitable for induction of persistent firing. Therefore, our study indicates that carbachol is necessary not only for postsubicular neurons to show strong persistent firing but also to be depolarized to near threshold membrane potential, suggesting that cholinergic modulation is necessary for the head direction cells to maintain current head direction. Indeed, a recent study has shown that blockade of muscarinic and serotonergic transmission disrupts the directional tuning of anterior thalamic head direction cells (Sandoval et al., 2008). Their data after blockade suggests that head direction cells are underestimating the movement of the head, which could be accounted for by the lack of persistent activity.

Persistent firing has been studied in other systems such as nucleus prepositus hypoglossi, medial vestibular nucleus (McFarland and Fuchs, 1992), and area I neurons (Aksay et al., 2001) in the brainstem nuclei. Neurons in these studies code eye position by frequency of persistent firing. These neurons often fire at high-frequency for a short-duration (50-100 ms) at the beginning of persistent firing, suggesting that transient synaptic input triggers persistent firing in these neurons. This suggests that single cell mechanisms reported in our study could exist in these systems. However, current injection in a single neuron does not initiate persistent firing in area I neurons (Aksay et al., 2001). This suggests that persistent firing in the area I neuron requires synaptic connections.

In this study, we used calcium-free ACSF and flufenamic acid to investigate the involvement of $I_{\mathrm{CAN}}$ in persistent firing. It should be noted, however, that flufenamic acid is reported to have nonselective effects such as inhibition of calcium current (Wang et al., 2006). A recent study using more specific pharmacological agent is unveiling molecular correlates for the $I_{\text {CAN }}$ in the entorhinal cortex as the mechanism for persistent firing (Zhang et al., 2008). Similar pharmacological study in the postsubiculum will give more detailed insight into the mechanism for persistent firing observed in our study.

Funahashi and Stewart (1997) reported basic electrophysiological properties of cells in the presubiculum. However, they did not test for persistent firing properties. In this study, we found that the sag potential is larger in deeper layer cells than in superficial cells in the postsubiculum. Although Funahashi and Stewart (1997) reported the existence of sag potential, they did not report differences between superficial and deep layers. This could be because they did not have a sufficient number of cells to analyze the difference, but it could also be because Funahashi and Stewart (1997) recorded from all of the presubiculum, not limiting themselves to the dorsal part, whereas we specifically recorded from the postsubiculum (dorsal presubiculum). No cells showed repeated bursting in our study across all layers under current injection. This agrees with the study by Funahashi and Stewart (1997) and the fact that Taube et al. (1990a) did not find "complex spiking" in head direction cells.

We found that the spike frequency adaptation ratio was cor- related with the frequency of persistent firing. Since the AHP currents regulate spike frequency adaptation (Madison and Nicoll, 1984; Khawaja et al., 2007), these results suggest that the amount of AHP currents play a key role in controlling persistent firing. In fact, it is suggested by a modeling study that the ratio of AHP current versus $I_{\text {CAN }}$ controls persistent firing (Fransén et al., 2006). Interestingly, Taube and Muller (1998) reported that head direction cells in the postsubiculum do not show significant adaptation. This agrees with our hypothesis that head direction cells have an ability to show persistent firing supported by an intrinsic mechanism studied in this paper.

Finally, our finding of intrinsic persistent firing in the postsubiculum does not exclude the contribution of synaptic transmission or external input from other structures to the head direction system in maintaining persistent firing. Synaptic transmission or external input will be needed to form head direction-sensitive firing. Our study, rather, suggests that the mechanism for persistent firing in the head direction system could arise at the single cell level. Understanding the potential combined role of intrinsic persistent firing and synaptic interactions between neurons could lead to better understanding of the head direction system and the role of postsubiculum in navigation and spatial memory.

\section{References}

Aksay E, Gamkrelidze G, Seung HS, Baker R, Tank DW (2001) In vivo intracellular recording and perturbation of persistent activity in a neural integrator. Nat Neurosci 4:184-193.

Al-Yahya E, Hamel E, Kennedy TE, Alonso AA, Egorov AV (2003) Persistent activity in entorhinal cortex neurons induced by muscarinic and metabotropic glutamate receptor activation and its dependent on TRP channels. Soc Neurosci Abstr 29:375.

Blair HT, Sharp PE (1995) Anticipatory head direction signals in anterior thalamus: evidence for a thalamocortical circuit that integrates angular head motion to compute head direction. J Neurosci 15:6260-6270.

Blair HT, Cho J, Sharp PE (1998) Role of the lateral mammillary nucleus in the rat head direction circuit: a combined single unit recording and lesion study. Neuron 21:1387-1397.

Boccara CN, Sargolini F, Hult V, Witter MP, Moser EI, Moser MB (2008) Grid cells in presubiculum and parasubiculum. FENS Abstr 4:128.121.

Boucheny C, Brunel N, Arleo A (2005) A continuous attractor network model without recurrent excitation: maintenance and integration in the head direction cell system. J Comput Neurosci 18:205-227.

Brandon MP, Andrews CM, Hasselmo ME (2008) Postsubicular neural activity during REM sleep shows replay of head direction activity during waking. Soc Neurosci Abstr 34:94.14.

Burgess N, Barry C, O’Keefe J (2007) An oscillatory interference model of grid cell firing. Hippocampus 17:801-812.

Egorov AV, Hamam BN, Fransén E, Hasselmo ME, Alonso AA (2002) Graded persistent activity in entorhinal cortex neurons. Nature 420:173-178.

Fransén E, Tahvildari B, Egorov AV, Hasselmo ME, Alonso AA (2006) Mechanism of graded persistent cellular activity of entorhinal cortex layer v neurons. Neuron 49:735-746.

Funahashi M, Stewart M (1997) Presubicular and parasubicular cortical neurons of the rat: electrophysiological and morphological properties. Hippocampus 7:117-129.

Gee CE, Benquet P, Gerber U (2003) Group I metabotropic glutamate receptors activate a calcium-sensitive transient receptor potential-like conductance in rat hippocampus. J Physiol 546:655-664.

Goodridge JP, Touretzky DS (2000) Modeling attractor deformation in the rodent head-direction system. J Neurophysiol 83:3402-3410.

Goodridge JP, Dudchenko PA, Worboys KA, Golob EJ, Taube JS (1998) Cue control and head direction cells. Behav Neurosci 112:749-761.

Hasselmo ME (2008) Temporally structured replay of neural activity in a model of entorhinal cortex, hippocampus and postsubiculum. Eur J Neurosci 28:1301-1315.

Hasselmo ME, Brandon MP (2008) Linking cellular mechanisms to behavior: entorhinal persistent spiking and membrane potential oscillations 
may underlie path integration, grid cell firing, and episodic memory. Neural Plast 2008:658323.

Hasselmo ME, Giocomo LM, Zilli EA (2007) Grid cell firing may arise from interference of theta frequency membrane potential oscillations in single neurons. Hippocampus 17:1252-1271.

Khawaja FA, Alonso AA, Bourque CW (2007) $\mathrm{Ca}(2+)$-dependent $\mathrm{K}(+)$ currents and spike-frequency adaptation in medial entorhinal cortex layer II stellate cells. Hippocampus 17:1143-1148.

Klink R, Alonso A (1997) Muscarinic modulation of the oscillatory and repetitive firing properties of entorhinal cortex layer II neurons. J Neurophysiol 77:1813-1828.

Madison DV, Nicoll RA (1984) Control of the repetitive discharge of rat CA 1 pyramidal neurones in vitro. J Physiol 354:319-331.

Marrosu F, Portas C, Mascia MS, Casu MA, Fà M, Giagheddu M, Imperato A, Gessa GL (1995) Microdialysis measurement of cortical and hippocampal acetylcholine release during sleep-wake cycle in freely moving cats. Brain Res 671:329-332.

McFarland JL, Fuchs AF (1992) Discharge patterns in nucleus prepositus hypoglossi and adjacent medial vestibular nucleus during horizontal eye movement in behaving macaques. J Neurophysiol 68:319-332.

McNaughton BL, Chen LL, Markus EJ (1991) “dead reckoning," landmark learning, and the sense of direction: a neurophysiological and computational hypothesis. J Cogn Neurosci 3:190-202.

McNaughton BL, Battaglia FP, Jensen O, Moser EI, Moser MB (2006) Path integration and the neural basis of the 'cognitive map'. Nat Rev Neurosci 7:663-678.

Mesulam MM, Mufson EJ, Wainer BH, Levey AI (1983) Central cholinergic pathways in the rat: an overview based on an alternative nomenclature (Ch1-Ch6). Neuroscience 10:1185-1201.

Ranck JJ (1984) Head direction cells in the deep layer of dorsal presubiculum in freely moving rats. Soc Neurosci Abstr 10:599.

Redish A, Elga A, Touretzky D (1996) A coupled attractor model of the rodent head direction system. Network 7:671-685.

Rubin J, Terman D, Chow C (2001) Localized bumps of activity sustained by inhibition in a two-layer thalamic network. J Comput Neurosci 10:313-331.

Sandoval K, McDaniel KM, Murawski NJ, Doerr CE, Calton JL (2008) Combined blockade of serotonergic and muscarinic transmission disrupts the anterior thalamic head direction signal. Behav Neurosci 122:1226-1235.

Sharp PE (1996) Multiple spatial/behavioral correlates for cells in the rat postsubiculum: multiple regression analysis and comparison to other hippocampal areas. Cereb Cortex 6:238-259.

Skaggs WE, Knierim JJ, Kudrimoti HS, McNaughton BL (1995) A model of the neural basis of the rat's sense of direction. Adv Neural Inf Process Syst 7:173-180.
Song P, Wang XJ (2005) Angular path integration by moving "hill of activity": a spiking neuron model without recurrent excitation of the headdirection system. J Neurosci 25:1002-1014.

Stackman RW, Taube JS (1997) Firing properties of head direction cells in the rat anterior thalamic nucleus: dependence on vestibular input. J Neurosci 17:4349-4358.

Stackman RW, Taube JS (1998) Firing properties of rat lateral mammillary single units: head direction, head pitch, and angular head velocity. J Neurosci 18:9020-9037.

Stackman RW, Clark AS, Taube JS (2002) Hippocampal spatial representations require vestibular input. Hippocampus 12:291-303.

Tahvildari B, Fransén E, Alonso AA, Hasselmo ME (2007) Switching between "On" and "Off" states of persistent activity in lateral entorhinal layer III neurons. Hippocampus 17:257-263.

Tahvildari B, Alonso AA, Bourque CW (2008) Ionic basis of ON and OFF persistent activity in layer III lateral entorhinal cortical principal neurons. J Neurophysiol 99:2006-2011.

Taube JS (2007) The head direction signal: origins and sensory-motor integration. Annu Rev Neurosci 30:181-207.

Taube JS, Bassett JP (2003) Persistent neural activity in head direction cells. Cereb Cortex 13:1162-1172.

Taube JS, Muller RU (1998) Comparisons of head direction cell activity in the postsubiculum and anterior thalamus of freely moving rats. Hippocampus 8:87-108.

Taube JS, Muller RU, Ranck JB Jr (1990a) Head-direction cells recorded from the postsubiculum in freely moving rats. I. Description and quantitative analysis. J Neurosci 10:420-435.

Taube JS, Muller RU, Ranck JB Jr (1990b) Head-direction cells recorded from the postsubiculum in freely moving rats. II. Effects of environmental manipulations. J Neurosci 10:436-447.

van Groen T, Wyss JM (1990) The postsubicular cortex in the rat: characterization of the fourth region of the subicular cortex and its connections. Brain Res 529:165-177.

Wang D, Grillner S, Wallén P (2006) Effects of flufenamic acid on fictive locomotion, plateau potentials, calcium channels and NMDA receptors in the lamprey spinal cord. Neuropharmacology 51:1038-1046.

Yoshida M, Fransén E, Hasselmo ME (2008) mGluR-dependent persistent firing in entorhinal cortex layer III neurons. Eur J Neurosci 28:1116-1126.

Zhang K (1996) Representation of spatial orientation by the intrinsic dynamics of the head-direction cell ensemble: a theory. J Neurosci 16:2112-2126.

Zhang Z, Reboreda A, Alonso A, Baker P, Seguela P (2008) TRPC channels mediate persistent activity in layer $\mathrm{V}$ principal neurons of the medial entorhinal cortex. Soc Neurosci Abstr 34:240.6/E28. 